\title{
Sobre las lenguas de los judíos en la España visigoda y al-Andalus
}

\author{
Carlos DeL VALLE* \\ Instituto de Filología - CSIC, Madrid
}

En un estudio reciente, el Prof. David J. Wasserstein se ha pronunciado sobre el problema de las lenguas de los judíos españoles en la Alta Edad Media, en la España visigoda y en al-Andalus ${ }^{1}$. Algunas de sus afirmaciones me han resultado sorprendentes, también por la rotundidad con la que se hacen, y por ello me ha parecido conveniente contrastar sus opiniones con algunos datos que pueden contribuir a clarificar el asunto. Siguiendo la exposición del propio Wasserstein, diferenciaré la España visigoda de la España islámica.

\section{LAS LENGUAS DE LOS JUDÍOS EN LA ESPAÑA VISIGODA}

En este punto, Wasserstein dice que se puede afirmar, con toda certeza, que los judíos españoles carecían casi por completo de cul-

\footnotetext{
*cvalle@filol.csic.es.

1 «Langues et frontières entre juifs et musulmans en al-Andalus», en Judíos $y$ musulmanes en al-Andalus y el Magreb. Contactos intelectuales, ed. M. FIERro (Madrid 2002) págs. 1-11.

Sefarad 63 (2003) págs. 183-193

(c) CSIC

ISSN 037-0894
} 
tura judía, y que, a diferencia de sus correligionarios orientales, no estaban en condiciones de utilizar las formas lingüísticas de expresión cultural, el hebreo y el arameo: «Mais s'il y a une chose que l'on peut affirmer sans risque d'erreur, c'est que les juifs de l'Espagne wisigothique ne savaient presque rien de la culture juive et, de surcroît, qu'ils ne savaient guère utiliser les formes linguistiques d'expression culturelle que leurs correligionnaires du monde oriental employaient dans les grand centres de la vie juive à cette époque, c'est-à-dire l'hébreu et l'araméen» (pág. 3).

Niega Wasserstein que se haya transmitido ni un solo testimonio sobre la vida cultural de los judíos de la España visigoda («Pour en revenir aux juifs de l'Espagne wisigothique, nous ne possédons pas un seul témoignage sur la vie culturel de ces juifs»). Según este autor, los judíos españoles sólo conocían y hablaban el bajo latín hispano, y del hebreo sólo conocían alguna palabra suelta, como shalom, Israel, álenu y poco más, aproximadamente lo que hoy un profano en eslavística puede conocer del ruso (da, niet, datcha...): «On peut affirmer avec une quasi certitude que les juifs de l'Espagne wisigothique ne connaissaient et ne pratiquaient qu'une seule langue, et que cette langue n'était autre que celle de leurs voisins, c'est-à-dire le bas latin de la période. Certes, ils savaient quelques mots rares que tous les juifs connaissent -shalom, Israel et aussi peut-être '́lenu et rien de plus-, mais cela n'est pas une langue et n'atteste en rien la capacité à manier une langue» (pág. 4).

Lamentablemente, no puedo participar de estas opiniones del Prof. Wasserstein. Son demasiado radicales y, por otra parte, no resisten su confrontación con la realidad documental.

Estoy de acuerdo con D. J. Wasserstein en que de los judíos españoles de aquella época no se nos ha transmitido ni un solo texto, ni en hebreo ni en bajo latín. Quien conozca la historia de los judíos españoles en el período visigodo, sobre todo a raíz de la conversión de Recaredo, puede encontrar fácilmente una explicación a este hecho. Pero de ahí no se puede concluir sin más que los judíos españoles del período visigodo no cultivaran una literatura en hebreo o en bajo latín. 
También coincido con este autor en que las escasas inscripciones hebraicas del período visigodo no son suficientes para hacer ninguna conjetura seria sobre su cultura judaica o sobre su conocimiento del hebreo ${ }^{2}$. Y también admito que para dilucidar este asunto no se puede echar mano de leyendas, que las hay, como la que transmite hacia mediados de la décima centuria el gaón de Pumbedita Aharón ha-Cohen ben Sargada (m. 960), que habla de un cúmulo importante de sabios judíos en la España antigua en época de Alejandro Magno y en el período mísnico ${ }^{3}$.

Sin embargo, pasando ya a los datos documentales, en la disputa que S. Julián de Toledo (m. 690) mantuvo con los judíos hispanos acerca de la edad mesiánica, y que ha quedado recogida en su $D e$ comprobatione sextae aetatis, redactado en el año $686^{4}$, el arzobispo toledano afirma que los judíos españoles contemporáneos suyos poseían códices hebreos. Partiendo de los códices hebreos, los judíos argüían que se encontraban todavía en la quinta edad del mundo, en el quinto milenio (en el año 4446 de la creación, 686 de la era cristiana): Quod sumpta annorum supputatio -decían- ab initio mundi secundum codices hebraeos quintam adhuc saeculi aetatem insinuent ${ }^{5}$.

Pero los judíos españoles no disponían de códices hebreos que guardasen como piezas de museo intocables en una urna de cristal, sino que se servían de ellos para su argumentación sobre la edad

2 Véase F. CANTERA y J. M. Millás, Inscripciones hebraicas de España (Madrid 1956); M. SCHWAB, Rapport sur les inscriptions hébräques de l'Espagne (Paris 1907).

3 La carta del gaón fue publicada por A. Cowley («Bodleian Geniza Fragments», The Jewish Quarterly Review 18 [1906] págs. 399-403), y nosotros hemos ofrecido una traducción castellana en La escuela hebrea de Córdoba (Madrid $1981)$ págs. 366 ss.

4 Editado por J. N. Hillgarth, Sancti Juliani Toletanae Sedis Episcopi Opera, Corpus Christianorum, Series latina, vol. 115 (Turnholti 1976) [en adelante, De comprobatione].

${ }^{5}$ De comprobatione, Prefacio, lín. 27 (pág. 145). 
mesiánica. S. Julián lo dice expresamente cuando afirma que el cálculo de los años lo extraían de los códices hebreos: Ergo anni illi, quos a principio mundi pro hac nativitate christi ex codicibus hebraeorum libandos esse putatis ${ }^{6}$. Por tanto, los judíos españoles tenían que saber mucho hebreo como para poder utilizar los códices hebreos y poder sustentar en ellos una disputa con los cristianos.

Entre aquellos códices hebreos, algunos eran ciertamente bíblicos. Esto resulta claro cuando S. Julián contrapone, por una parte, el cómputo de los años del mundo según los códices hebreos (el texto hebreo bíblico) y, por otra, el cómputo según la versión de los LXX (Ecce minor numerus reperitur annorum in codicibus hebraeorum quam in codicibus septuaginta interpretum) ${ }^{7}$.

Pero entre aquellos códices hebreos tenía que haber otros que no eran bíblicos, ya que con ellos los judíos españoles establecían que el Mesías había de venir en la sexta edad del mundo, es decir, a partir del año 5000 de la creación. Así lo expresaba S. Julián: Quod sumpta annorum supputatio -decían- ab initio mundi secundum codices hebraeos quintam adhuc saeculi aetatem insinuent et necdum adhuc christum venisse, quem in sexta credunt aetate saeculi advenire ${ }^{8}$. La hipótesis de que parte de los códices hebreos utilizados por los judíos hispanos no eran bíblicos se ve ratificada por el hecho de que el arzobispo toledano afirma que las Sagradas Escrituras no tienen ningún cálculo sobre la venida del Mesías partiendo de la creación del mundo (quia nihil tale aut in lege aut in prophetis praedictum est, ut supputatis a mundi principio annis adventus dinoscatur dominicae incarnationis) ${ }^{9}$ y que él no quiere embarcarse en ninguna discusión que no se asiente en las Sagradas Escrituras (Vere multum stulta est quaestio, quae de legis non procedit arcano. Imbelles ergo et inermes

\footnotetext{
${ }^{6}$ De comprobatione, I.23 (pág. 170).

7 De comprobatione, III.8 (pág. 201).

8 De comprobatione, Prefacio, lín. 26-30 (pág. 145).

9 De comprobatione, I.6 (pág. 152).
} 
huiusmodi iudicandi sunt, quia non de scripturis arma arripiunt, sed de antro malitiae suae ista proponunt) ${ }^{10}$.

Entiendo, pues, que es una hipótesis razonable y fundamentada aceptar que los judíos españoles del período visigodo disponían y manejaban códices hebreos bíblicos y extrabíblicos, y que eso suponía que sabían mucho hebreo.

Pero aún hay más. Los judíos españoles afirmaban, sobre la base de sus códices hebreos, que el Mesías vendría en la sexta edad del mundo (quem in sexta credunt aetatem saeculi advenire), esto es, en el sexto milenio de la creación. Esta concepción difiere sustancialmente de la que sostenían sus correligionarios palestinos y babilónicos, según la cual el mundo duraría siete mil años; de ellos, los dos mil primeros serían sin Ley, los dos mil siguientes con la Ley, y los otros dos mil años serían del Mesías (desde 4000 a 5999). El séptimo milenio sería el reino totalmente mesiánico. Estas concepciones se expresan al menos en tres lugares talmúdicos (bSan 97a; bAZ 9a; bRhSh 31a).

Yo creo que es razonable admitir, partiendo de estos hechos, que el Talmud babilónico, hacia los años ochenta de la séptima centuria, no se había introducido todavía en España, ni había adquirido el carácter autorizado que tendría después, probablemente porque en aquella época el Talmud babilónico estaba todavía in fieri y no se había cerrado definitivamente el proceso de su formación. Por otra parte, las concepciones de los judíos españoles parecen autóctonas, diferentes de las de sus correligionarios palestinos y babilónicos. Por lo que es igualmente razonable y fundado admitir que los judíos españoles desarrollaron una cultura y una literatura hebrea autóctonas ${ }^{11}$.

\footnotetext{
${ }^{10}$ De comprobatione, I.2 (pág. 149).

${ }^{11}$ Reenvío a mis dos estudios, «El De comprobatione sextae aetatis de Julián de Toledo y el judaísmo español», Estudios Bíblicos 49 (1991) págs. 251-263 y «San Julián de Toledo», en La controversia judeocristiana en España (Desde los orígenes hasta el siglo XIII), ed. C. DEL VALLE (Madrid 1998) págs. 119-130.
} 
Se confirma la existencia de una literatura judía en la España visigoda por una de las leyes del Fuero Juzgo, decretada por el rey Ervigio (m. 687). Después de señalar que el gusto por la lectura de libros indebidos es un indicio de impiedad más que de piedad, ordena que si un judío-converso (un cristiano nuevo) «leyere aquellos libros de los judíos o prestare atención a sus doctrinas o los tuviere escondidos en sus casas, en los cuales se opina mal de la fe cristiana, será públicamente decalvado y será castigado con cien azotes» ${ }^{12}$.

Lo que esta ley confirma es que existían iudaeorum libros -una literatura judía- entre los judíos españoles, sin que podamos precisar si aquellas obras estaban redactadas en el bajo latín hispano o en hebreo.

Ciertamente, la documentación que aporto es todavía bastante exigua, aunque relevante y contundente, y convendría ampliarla con la investigación de otros autores y documentos del período visigodo. En cualquier caso, de los datos aducidos parece haber quedado suficientemente probado que los judíos españoles del período visigodo conocían bien el hebreo y tenían una literatura propia. Además, como hipótesis razonable, parece que los judíos hispanos de aquella época fueron creadores de una literatura hebrea autóctona. Quizás a esta luz se entiendan más profundamente las palabras de Samuel ha-Naguid (m. 1056), quien afirmaba que «Sefarad fue un lugar de estudio de la Torá desde los tiempos primeros, desde el destierro de Jerusalén hasta ahora» ${ }^{13}$.

\footnotetext{
${ }^{12}$ Et ideo si quis Iudaeorum libros illos legerit vel doctrinas adtenderit sive habitos in domo sua celaverit, in quibus male contra fidem Christi sentitur et publice decalvabitur et centenorum flagellorum verberatione plectetur: $\mathrm{K}$. ZEUMER, Monumenta Germaniae Historica Legum sectio prima... I. Leges visigothorum (Hannover - Leipzig 1902) pág. 438 (Ley XI: Ne iudei libros illos legere audeant, quos christiana fides repudiat).

${ }^{13}$ Judá bar Barzillay, Sefer ha- 'Ittim, ed. Y. SHOR (Berlin 1903) pág. 267.
} 
Hay también una certeza razonable de que los judíos españoles del período visigodo no abandonaron la lectura del Targum y que, consiguientemente, hubo muchos que conocían el arameo. La obligación de la lectura del Targum ya procede al menos del período mísnico. Sobre la práctica de la lectura del Targum en España tenemos el testimonio tardío de Judá Ibn Qoreish (s. X) en el prefacio a su risâla a la comunidad judía de Fez sobre la lectura del Targum: «no descuidaron sus enseñanzas vuestros antecesores en ... Sefarad» ${ }^{14}$. Pero más interés para nuestra cuestión tiene el testimonio de Samuel ha-Naguid, que remonta la práctica de la lectura del Targum en España a una época remotísima ${ }^{15}$.

Para completar nuestra imagen de las lenguas de los judíos en la España visigoda, he de anotar que algunos grupos judíos hispanos hablaban griego, probablemente venidos a Iberia desde la diáspora helénica. Melecio, el hermano de Teodoro, jefe de la comunidad judía de Mahón (principios del siglo v), dice de Inocencio, un judío que había dejado la península por razón de las guerras y luchas: «Sé que eres conocedor no sólo del latín sino también del griego» (Ego te ... Innocenti frater qui non solum Latinis, verum etiam graecis litteris eruditus es ...) ${ }^{16}$.

Algunos epitafios, como los de Tortosa y Elche, confirman la presencia de un grupo judío hispano de origen helénico que en buena medida hablaba griego ${ }^{17}$.

\footnotetext{
${ }^{14}$ Dan BeCKer, Ha-Risâla shel Yehuda ben Quraisch (Tel Aviv 1986) pág. 116. Véase mi traducción castellana del prefacio en La escuela hebrea de Córdoba (Madrid 1981) págs. 634 ss.

${ }^{15}$ Judá bar Barzillay, Sefer ha-'Ittim, pág. 267; C. DEL VALLE, Historia de la Gramática Hebrea en España, I. Los orígenes (Madrid 2002) pág. 216.

${ }^{16}$ G. SEguí VidAL, La Carta-Encíclica del obispo Severo (Palma de Mallorca 1937) lín. 428. A juzgar por los nombres, la propia familia de Teodoro podría proceder de la diáspora helénica.

${ }^{17}$ S. KATZ (The Jews in the Visigothic and Frankish Kingdoms of Spain and Gau. [Cambridge, Mass. 1937] pág. 62) afirma que en el placitum que los judíos conversos juraron ante Chintila en 637 aparecía una referencia a la Misná bajo el nombre
} 
Lamentablemente, carecemos de un mayor apoyo documental que nos permita delimitar el alcance y extensión de aquellos conocimientos. Cuando en 949 el emperador Constantino VII Porfirogénitos (945-59) envía al califa Abderramán III un ejemplar del De materia medica de Dioscórides en la lengua original griega, nos recuerda Ibn Yuyul que entre los cristianos de Córdoba no había ninguno que supiera griego ${ }^{18}$; evidentemente, tampoco lo había entre los judíos, puesto que el Emperador tuvo que enviar a Córdoba, un año después, al monje Nicolás para ayudar en la traducción del Dioscórides, en cuya empresa estuvo muy activo Hasday Ibn Shaprut ${ }^{19}$.

\section{LAS LENGUAS DE LOS JUDÍOS DE AL-ANDALUS}

En cuanto a los judíos en la España islámica, D. J. Wasserstein hace aseveraciones también sorprendentes. Afirma que «les juifs -ou tout au moins les juifs producteurs de culture- étaient presque exclusivement concentrés à Cordoue et à Lucene» (pág. 11), y pasa por alto centros tan importantes para la cultura hebraica en la España islámica como Toledo, Zaragoza, Granada, Málaga, Játiva o Mérida.

En la España islámica -dice este autor- los judíos andalusíes aprendieron simultáneamente dos lenguas nuevas. Por una parte el árabe, la lengua de los dominadores, que se convertiría en la lengua de uso cotidiano y profano, y por otra la lengua hebrea para «usos culturales restringidos»:

\footnotetext{
griego de deuterai, lo cual es un testimonio elocuente de la presencia del griego entre la población judía hispana.

${ }^{18} \mathrm{~J}$. VERNET, «Los médicos andaluces en el libro de las generaciones de médicos de Ibn Yulyul», Anuario de Estudios Medievales 5 (1968) pág. 447; C. DEL VAlle, La escuela hebrea, pág. 62. Sí hay testimonios de estudiosos hispanos de la España cristiana que se trasladaron a Constantinopla y aprendieron griego. S. Isidoro de Sevilla (m. 636) cuenta de Iohannes, obispo de Gerona y natural de Lusitania, que vivió bajo el reinado de Leovigildo (m. 586): Hic, cum esset adolescens, Constantinopolim perrexit, ibique graeca et latina eruditione nutritus, septimo demum anno in Hispanias reversus est (De viris illustribus XXXI, ed. C. CODOÑER MERINO [Salamanca 1964]).

${ }^{19}$ C. DEL VALLE, La escuela hebrea, pág. 60 ss.
} 
L'acquisition quasi simultanée par tout un groupe (ou plutôt par tout un groupuscule) -ou, plus précisément, pour tout l'élite culturel d'un tel groupe (ou groupuscule)-, non pas d'une langue nouvelle mais de deux langues nouvelles, don't l'une était réservée à des utilisations culturelles très restreintes, voilà que constitue un problème (pág. 10).

El aprendizaje del árabe fue un fenómeno similar al ocurrido con otras lenguas de la diáspora judía, como el arameo en Babilonia, o el griego en el mundo helenístico. Únicamente que la comunidad judía andalusí, por razones sociológicas, aprendió el árabe con más rapidez que otros grupos minoritarios.

La reavivación del hebreo en la España islámica -expone el Prof. Wasserstein- es un fenómeno cultural extraordinario que, en parte ahora, se puede entender más fácilmente tras la experiencia de la revitalización del hebreo en nuestra edad contemporánea. Pero si los judíos hispanos de la España visigoda no sabían hebreo, si tampoco hubo como tal una inmigración notable en la España islámica, ¿de dónde adquirieron entonces el conocimiento tan profundo y tan extenso que tuvieron del hebreo las élites judías de aquel período? Para Wasserstein, este problema es un enigma que sólo tiene una solución parcial en la apertura de las comunidades judías de alAndalus a otras comunidades del exterior, proceso posibilitado por la prosperidad económica del país.

Sin embargo, ya he dicho que el punto de partida del Prof. Wasserstein -la suposición de que los hebreos españoles de la época visigoda no sabían nada de hebreo- no es acertado. Tenemos testimonios de la ocupación de los judíos españoles en los estudios judaicos desde el principio mismo del establecimiento del poder islámico en España, en los siglos VIII y IX, y a raudales a partir del siglo X. Valga como botón de muestra la experiencia del diácono alemán Bodón. Éste vino a Zaragoza en 838, se hizo judío, se casó con una judía y se alistó en el ejército musulmán. Bodón, que tomaría por nombre Elazar, aprendió la lengua hebrea, estudió comentarios bíblicos y derecho rabínico. Sus progresos en la lengua hebrea 
fueron tan notables que suscitaron el comentario de Álvaro de Córdoba, su contrincante en una acalorada polémica. Pues bien, Álvaro de Córdoba constataba, no sin cierta acritud, que Bodón había conseguido una maestría sobre el hebreo: Miror te eruditionis in hebraea lingua tam velox peritia ${ }^{20}$. Significa esto que en la Zaragoza de principios del siglo IX había una comunidad judía que conocía el hebreo y que tenía los medios para enseñarlo con éxito.

Hay que señalar, además, que la aparición y desarrollo de la gramática científica del hebreo es un fenómeno fundamentalmente hispano que surge en la escuela del tortosino Menahem ben Saruq. Bien es verdad que los fundamentos de la gramática científica del hebreo los ponen los discípulos de Menahem al calor de su disputa sobre el metro cuantitativo de origen árabe introducido por Dunash ben Labrat. Todos los elementos que servirán de base a Hayyûğ para establecer el principio revolucionario del triliteralismo verbal hebreo -la doctrina del nah ne élam y del nah nir'e, la intercambiabilidad de las consonantes débiles hwy ...- fueron establecidos ya claramente por los discípulos de Menahem ${ }^{21}$. Quiero decir que Hayyûğ, que según las fuentes procedía de Fez, no importó de África sus innovaciones gramaticales, sino que vino muy joven a Córdoba, se formó en la escuela de Menahem y sólo ya en su vejez llegó a escribir sus dos obras revolucionarias, el Kitâb al-af'âl dawât hurûf al-lîn y el Kitâb al-afâl dawât al-mițlayn. En esas obras, sin negar influjos de algunos gramáticos árabes, recogió las doctrinas de la escuela de Menahem y las coronó con su intuición novedosa.

Basten estas notas para ofrecer un punto de reflexión y de crítica a algunas de las afirmaciones vertidas por el Prof. Wasserstein en su reciente artículo.

\footnotetext{
${ }^{20}$ J. MAdOZ, Epistolario de Álvaro de Córdoba (Madrid 1947) Carta XVI,I.

${ }^{21}$ C. DEl VAlle, Historia de la Gramática Hebrea, vol. I, págs. 354 s.
} 


\section{RESUMEN}

El Prof. David J. Wasserstein ha afirmado en un reciente artículo que, con toda certeza, puede decirse que los judíos de la España visigoda carecían de una cultura judía y no conocían el hebreo. En cuanto a los judíos de la España musulmana, habrían aprendido simultáneamente dos lenguas, el hebreo y el árabe. Así, según Wasserstein, el aprendizaje del hebreo plantearía un problema, ya que los judíos de la España visigoda no conocían el hebreo y en la España musulmana no hubo una emigración judía reseñable. El autor del presente estudio trata de mostrar que las opiniones del Prof. Wasserstein sobre los puntos señalados no son sostenibles.

PALABRAS ClAVE: Lenguas de los judíos, España visigoda, España islámica.

\section{SUMMARY}

Prof. David J. Wasserstein has stated in a recent article that one can with all certainty say that the Jews of Visigothic Spain did not have a Jewish culture and had no knowledge of Hebrew. Concerning the Jews in Muslim Spain, he believes that they woud have simultaneously learnt two languages, Hebrew and Arabic. As a result, still according to Wasserstein, the learning of Hebrew would have been a problem, since the Jews of the Visigothic period did not know Hebrew and in Muslim Spain no relevant Jewish emigration took place. The present study reviews Prof. Wasserstein's opinions and attempt at showing that his arguments can not be supported by the evidence.

KEYWORDS: Languages of the Jews, Visigothic Spain, Islamic Spain. 